$\xi=-1$ 圆

\title{
The Effect of Silane Treatment on Rice Husk / Phenol Formaldehyde Particleboard Mechanical Properties
}

\author{
Marini Sawawi ${ }^{1 *}$, Nor Umirah Sudirman ${ }^{1}$, Siti Kudnie Sahari ${ }^{1}$, Mahshuri Yusof ${ }^{1}$, Magdalene Andrew ${ }^{1}$, \\ Nur Tahirah Razali ${ }^{1}$, Rohana Sapawi ${ }^{1}$, Kuryati Kipli ${ }^{1}$ \\ ${ }^{1}$ Faculty of Engineering, Universiti Malaysia Sarawak, 94300 Kota Samarahan, Sarawak, Malaysia \\ *Corresponding author E-mail :smarini@ unimas.my
}

\begin{abstract}
The effects of silane (3-aminopropyl triethoxy silane aqueous solution) treatment on the mechanical properties on rice husk particle board were investigated. Using phenol formaldehyde as the binder, the rice husks were treated at three different concentrations of silane $(0.5 \mathrm{wt} \%, 2 \mathrm{wt} \%, 5 \mathrm{wt} \%)$ and untreated rice husk was set as control. The samples were characterized using Scanning Electron Microscope (SEM), 3-point bending test and water absorption behavior in accordance to ASTM1037. FTIR analysis was performed to verify the presence of the characteristic functional groups of untreated rice husk and silane treated husk. The results show that the mechanical properties were increased with silane treatment concentration. The swelling characteristics also improved as the concentration of silane increases less water were absorbed. Surface morphology of rice husk shows that the surface of the composites become rougher as the concentration of treatment was increased for better adhesion between fibers and the matrix.
\end{abstract}

Keywords: Rice husk particleboard; silane treatment; flexural properties

\section{Introduction}

In recent years, Rice (Oryza sativa $L$.) is one of the main crops that cover around $1 \%$ of the earth's surface. Rice feeds billions of people as it is a primary source of food. Statistics show that, Asia region produced more than $90 \%$ of the total global rice production throughout 2010 to 2013 which was 725 million metric tons for the average annual global production of rice. Rice husk (RH) is a natural sheath that formed around rice during its growth. Just as rice grains are separated during rice processing which is milling, it will produce inexpensive rice husk as their byproduct. For every ton of rice made it is revealed that, around 0.23 tons of $\mathrm{RH}$ is produced [1]. At present, most of these residues are burnt in situ after harvest. The field burning of rice husk and other agriculture residues in wide areas not only results in serious environment issues, but also wastes precious resources. The application of natural fiber/filler such as agriculture residue can be seen in various sectors such as construction, automobile industry, furniture, and also packaging [1-3]. RH filled polymer composites have great resistance to termite and biological attack. Rice husk also has more preferable dimensional stability consequent to moisture and exposure. Faced with worldwide shortages of forest resources, environmental pollution and waste of biological resources resulting from field burning of rice husk and other agriculture residues, there has recently been a revival of interest in using these byproducts to produce building materials including composite panels. Deforestation, forest degradation and increasing wood-based panels demand has made agriculture residues such as RH to be considered as an alternative replacement for wood and wood-based board products. The use of RH is now becoming popular in the production of composites panels because of it high availability and ease to manufacture. The examples of products of using $\mathrm{RH}$ composites are particleboards, insulation boards and ceiling boards.
Construction industry used $\mathrm{RH}$ as main materials because of its unique compositions, resistance to weathering, low bulk density, toughness and abrasive in nature. This nature can decrease the mechanical properties of fibers. The mutually exclusive between the natural fibers (hydrophilic) and the thermoplastic matrices (hydrophobic) causes unwanted properties of composites. Therefore, a number of chemical surface treatments of fibers were conducted so that improvement of mechanical performance of fibers and composites can be done. The examples of chemical treatment done were silane treatment, alkali treatment, peroxide treatment and isocyanate. This research investigates the effect of silane treatment concentration on the flexural properties of rice husk/phenol formaldehyde particleboard.

\section{Materials and Method}

\subsection{Materials}

Rice husk were collected from a local farmer at Kampung Meranek, Kota Samarahan. The adhesive used was a water-soluble Phenol Formaldehyde resin (Hexachem, Malaysia). Rice husk were treated using 3-aminopropyl triethoxy silane $\left(\mathrm{C}_{6} \mathrm{H}_{17} \mathrm{NO}_{2} \mathrm{Si}\right)$ from Sigma Aldrich.

\subsection{Silane Treatment}

Silane treatment involved soaking of rice husk into diluted silane with distilled water at $0.5 \%, 2 \%$ and $5 \%$ concentration at room temperature for 24 hours. The treated $\mathrm{RH}$ then rinsed thoroughly with water to remove silane solution before sun dried for about 2 days. After drying process, weights of dried RH were measured 